\title{
PRIVATE LABELS - CUSTOMER PROFILE AND CHANGES IN TRADE DURING PANDEMIC
}

\author{
Marie SLABÁ \\ College of Polytechnics Jihlava, Czech Republic; marie.slaba@vspj.cz, ORCID: 0000-0001-9607-1521
}

Purpose: This article focuses on private labels, which play a crucial role in the retail market. This article aims to examine the market of private labels in the Czech Republic and reveal the customer profile of private labels in the Czech market.

Design/methodology/approach: This article incorporates the results of the author's research devoted to various aspects of private labels and trade. The author used an online questionnaire for the research. This questionnaire was divided into several parts and prepared based on the literature search of statistics, reports, papers, and scientific studies.

Findings: Large retail chains can achieve more than $30 \%$ of sales from private labels. The nature of the private label market is changing significantly. Therefore, the customer profile is changing too. The author's research revealed that the most critical segment for private labels is women, specifically single women with an income of up to $20,000 \mathrm{CZK}$, aged under 27-36, who live in medium-sized cities with up to 100,000 inhabitants.

Research limitations/implications: In the current Covid-19 pandemic, the results can contribute to more effective collaboration with customers. In the future, it is intended to develop research on other aspects that affect the operation of private labels.

Practical implications: It is clear from the research results that large retail chains should focus on certain specific segments, especially women with the above profile. According to research, this segment is the most crucial segment for retail chains and should focus on it.

Originality/value: The article focuses on the changes during the Covid-19 pandemic. At this time, there were changes in shopping behavior, which are listed in the article.

Keywords: private labels, customer profile, retail, customer.

Category of the paper: research paper.

\section{Introduction}

In the progressively growing competition in the retail markets, customer care and handling have become priorities for all organizations operating in this market. Knowledge of the customer's profile is essential not only for large retail chains but for smaller retailers, too. However, large retail chains are more concerned with this issue. To improve and strengthen 
their market position, retail chains are trying to invest considerable money in obtaining information about their customers.

Julashokri et al. (2011) reported that customer profile knowledge is an essential element of one-to-one marketing in marketing planning. Various models are often used in marketing planning to create suitable customer profiles, which Park and Chang (2009) argue can improve entire customer profiling systems. Lee and Yang (2003) emphasize that a well-known customer profile makes it possible to predict his/her future preferences. An understanding customer profile is one of the most important secrets of selling, not only in retail (Upadhyay, Vidhani, and Dadhich, 2016).

Since a detailed knowledge of the customer profile is necessary for every organization to survive, this article is devoted to this issue. The customer profile differs not only in different fields but also concerning the products or brands. The author pays attention to the retail market in this article, where private labels have a specific position. As Grosso and Castaldo (2015) stated, changes in retail have also brought about the growing importance of private labels in the competition of retail chains. The importance of private labels in the retail market is constantly growing; therefore, the author will focus on the customer buying retailers' private labels.

Retail represents an essential part of any economy in the world. Retailers represent any company that sells products or services to private customers (individuals and families) or businesses for direct consumption. Business activities can be carried in physical stores as well as alternatively online. The Covid-19 pandemic changed all markets, mainly due to government measures that often banned various goods in physical stores. For this reason, online retailing is becoming increasingly important. The following figure shows the development of retail trade volume during Covid-19 in the EU.

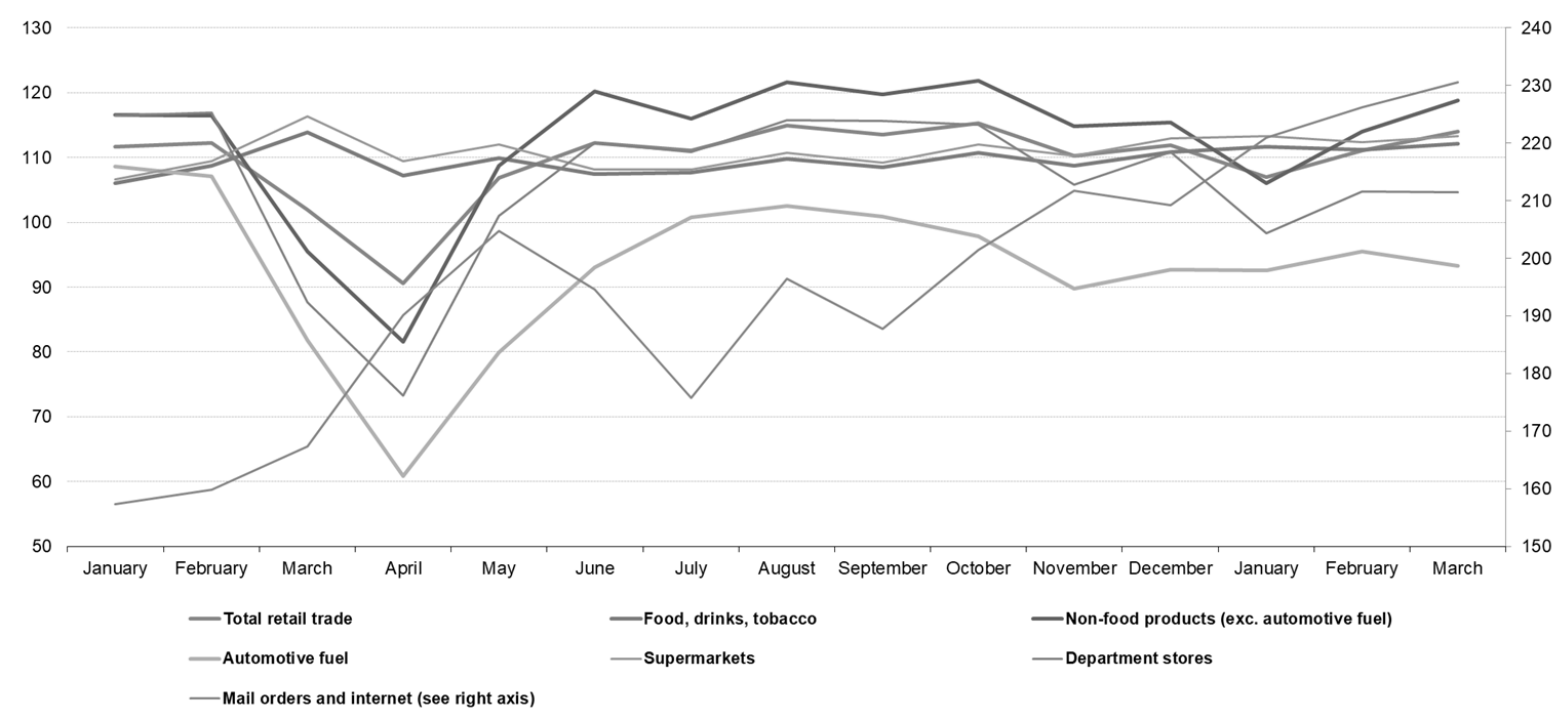

Figure 1. Development of retail trade volume in EU adapted from Eurostat (2021a). 
The most significant drop in sales was recorded by automotive fuel, non-food products, and department stores. The following table shows the month-on-month rate of change in trade volume according to selected product groups and total retail during March 2020 and December 2020.

Table 1.

Development of retail trade volume in EU (March 2020 - December 2020)

\begin{tabular}{|l|l|l|l|l|l|l|}
\hline & March & April & May & June & July & August \\
\hline total retail & -9.1 & -11.2 & 18 & 5.1 & -1.1 & 3.5 \\
\hline $\begin{array}{l}\text { non-food products (excluding } \\
\text { automotive fuel) }\end{array}$ & -18 & -14.6 & 33.3 & 10.5 & -3.5 & 4.8 \\
\hline automotive fuel & -23.6 & -25.7 & 31.4 & 16.5 & 8.3 & 1.7 \\
\hline department stores & -25 & -16.4 & 37.8 & 11.2 & -1.3 & 4.5 \\
\hline & September & October & November & December & September & October \\
\hline total retail & -1.2 & 1.5 & -4.3 & 1.5 & -1.2 & 1.5 \\
\hline $\begin{array}{l}\text { non-food products (excluding } \\
\text { automotive fuel) }\end{array}$ & -1.5 & 1.8 & -5.8 & 0.5 & -1.5 & 1.8 \\
\hline automotive fuel & -1.6 & -3.1 & -8.2 & 3.2 & -1.6 & -3.1 \\
\hline department stores & -0.2 & -0.4 & -8.1 & 4.7 & -0.2 & -0.4 \\
\hline
\end{tabular}

Source: own compilation based on Eurostat (2021b).

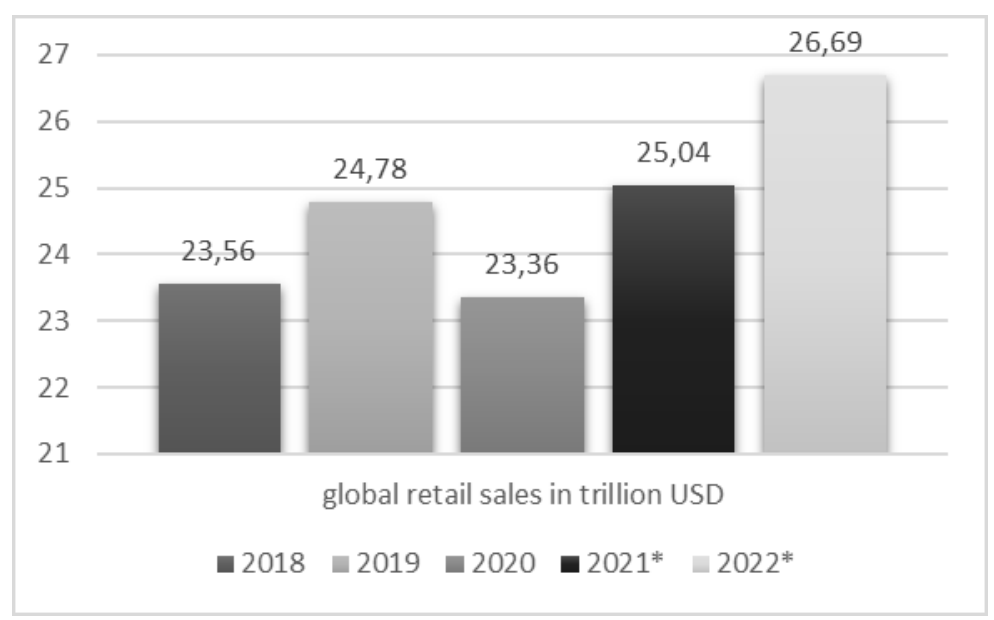

Figure 2. Global retail sales 2018-2022. Source: adapted from Statista (2021a).

If we focus on global overall retail sales, the impact of the COVID-19 pandemic is not so significant, and an increase is expected this year. Unfortunately, some sectors, see Table 1, was hit very hard and suffered significant losses. These losses are also why companies are increasingly focusing on customer profile issues to keep loyal customers.

The following figure shows the situation in the Czech Republic. 


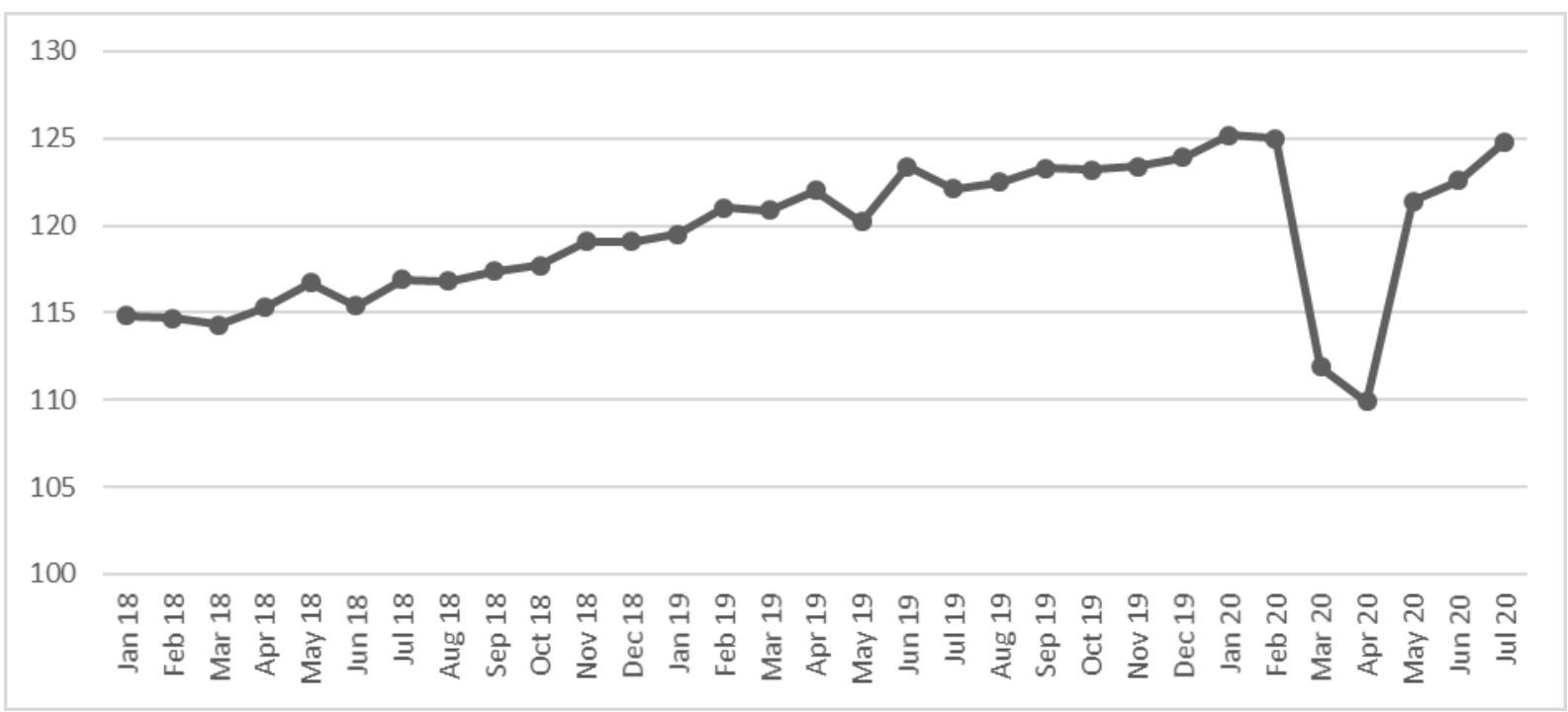

Figure 3. Monthly sales volume of total retail trade in the Czech Republic from January 2018 to July 2020 (as index*). Source: adapted from Statista (2021a).

As is clear from the previous chart, the situation in the Czech Republic also recorded a significant decline in total sales in March and April 2020, to values below the 110 index compared to the base year.

As mentioned in the Introduction, retail companies invest considerable resources to obtain detailed information about their customers. The aim is to obtain as much information as possible about customer profiles, which would lead to improved customer care, personalized offers, and thus ensuring the loyalty of existing customers and acquiring potential new customers.

Retail chains use various tools to obtain customer information, such as data mining techniques, customer databases, database marketing, loyalty programs, marketing surveys, or various modern technologies, applications, and expert methods. All these tools are then used to profile the end customer. Upadhyay, Vidhani, and Dadhich (2016, p. 65) define customer profiling as "a method to create a portrait of customers, including their personal and transactional details". Upadhyay, Vidhani, and Dadhich (2016) state that customer profiling is a necessary tool in customer-centered decisions. Customer profile data usually includes age, name, gender, salary, place of residence, and other geographic information Syakur et al. (2018).

The customer profile varies in different areas, as does his shopping behavior, closely related to the customer profile. This fact is also the reason why many authors deal with the customer profile in some specific regions. Many studies cover diverse areas like telecommunication, B2B market, insurance, energy, banking, retail, utility. Lee, Yo, and Chung (2011) focus on the customer profile in e-commerce. Planiappan et al. (2017) deal with customer profiling in the field of bank telemarketing. Wu et al. (2007) apply the customer profile integration based on ontology in telecommunications. Determining the right customer profile is a difficult task, which Vasilev (2014) claims in his research on the customer profile in the credit institution sphere. Some authors focus directly on the issue of customer profiles in the field of retail. We can include among these authors Chao, P. et al. (2008) and Prasad and Malik (2011). 
The fact that knowledge of the customer's profile is a crucial element shows that many authors and those mentioned above deal with this issue. Among others, we can mention, for example, Cordo (2012), Wehmeyer (2005), Risch and Schubert (2005), or Hassan and Tabasum (2018).

As indicated above, private labels play an important role in retail, as large retail chains can achieve more than $30 \%$ of sales from private labels The Nielsen Company (2018). The following figure summarises the latest statistics of supermarkets' private label sales in Europa by individual country.

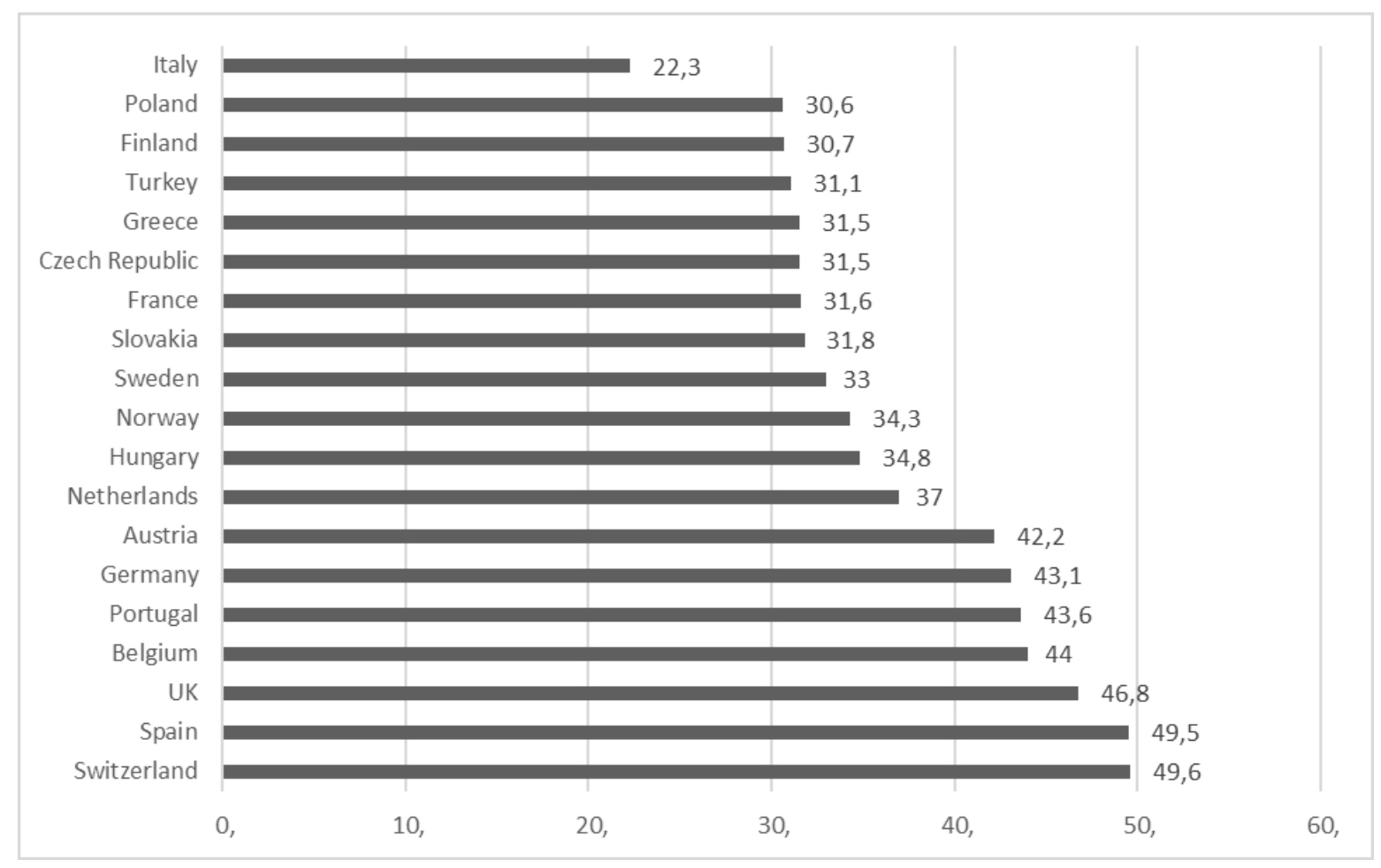

Figure 4. Supermarkets' sales volume of private labels in Europe 2020 in \%, Source: adapted from Statista (2021b).

As shown in the figure above, the penetration of private labels in the EU varies from country to country. The highest penetration is in Switzerland 49.6\%, Spain 49.5\%, United Kingdom $46.8 \%$. The penetration was higher than $40 \%$ reported in Austria, Germany, Portugal, and Belgium. The penetration of private labels in the Czech Republic has been growing and overturned $30 \%$ last year.

Furthermore, how can we define private labels? Based on the Cambridge English Dictionary, private labels are labels of goods produced by some manufacturer and sold using the name of the store. We can state that private labels are brands of retailers sold using the name of the retailer. Private labels aim to increase the number of loyal customers. Since the importance of private labels is growing, the number of researches, studies, and papers is increasing - for example, Cuneo et al. (2015), Kadirov (2020), Upadhyay, Vidhani and Dadhich (2016), Janssen and Hamm (2014). 


\section{Methods}

The author focuses on the private label, customer attitude towards private labels, categories of private labels, etc. This paper aims to present the author's research concerning the customer's profile buying private labels. Upadhyay, Vidhani, and Dadhich (2016) and other researchers stated that the customer profile is created based on customer research. Therefore, the author used marketing research to obtain data about the customers who are buying private labels. The author used an online questionnaire for the research. This questionnaire was divided into several parts and prepared based on the literature search of statistics, reports, papers, and scientific studies.

The first part of the questionnaire contained basic questions about private labels to reveal the customer's profile buying private labels. The second part of the questionnaire included the following characteristics of customer:

- age,

- profession,

- education,

- gender,

- number of family members,

- monthly income,

- place of residence by the number of inhabitants.

A total of 340 ( $42 \%$ of males and $58 \%$ of females) questionnaires were obtained and included in the analysis. The following tables characterize the distribution of respondents based on the selected characteristics.

Table 2.

Distribution of respondents according to the profession and education in \%

\begin{tabular}{|c|c|c|c|c|c|}
\hline \multirow{5}{*}{ Profession } & Student & $20 \%$ & \multirow{5}{*}{ Education } & Primary school & $8 \%$ \\
\hline & Employee & $40 \%$ & & High School & $28 \%$ \\
\hline & Entrepreneur & $22 \%$ & & University - bachelor & $34 \%$ \\
\hline & Pension & $10 \%$ & & University - master & $24 \%$ \\
\hline & Maternity leave & $8 \%$ & & University - Ph.D. & $6 \%$ \\
\hline
\end{tabular}

Source: author's research.

From the point of view of the profession, employees were the most represented group in the research. Entrepreneurs and students are represented by similar numbers, 20 and 22\%. The most numerous group were employees with a bachelor's degree. 
Table 3.

Distribution of respondents according to the number of household members and the average monthly income in \%

\begin{tabular}{|c|c|c|c|c|c|}
\hline \multirow{7}{*}{ Age } & less than 18 & $5 \%$ & \multirow{7}{*}{$\begin{array}{l}\text { Place of } \\
\text { residence by } \\
\text { number of } \\
\text { inhabitants }\end{array}$} & less than 500 & $8 \%$ \\
\hline & $18-26$ & $15 \%$ & & $501-5000$ & $12 \%$ \\
\hline & $27-36$ & $23 \%$ & & $5001-10000$ & $15 \%$ \\
\hline & $37-46$ & $26 \%$ & & $10001-50000$ & $22 \%$ \\
\hline & $47-56$ & $16 \%$ & & $50001-100000$ & $12 \%$ \\
\hline & $57-66$ & $10 \%$ & & $100001-500000$ & $8 \%$ \\
\hline & more than 66 & $5 \%$ & & $500001-1000000$ & $8 \%$ \\
\hline & & & & more than 1000000 & $15 \%$ \\
\hline
\end{tabular}

Source: author's research.

Almost half of the respondents belong to the age group 27-46 years. In the case of residence size, not all categories distinguished by the Czech Statistical Office were listed, but some were merged with regard to a large scope.

\section{Results and discussion}

In this part, the individual questions will be discussed in detail about the selected individual characteristics. First, respondents were asked whether they buy private labels and what goods they prefer, whether private or branded goods.

In the first part of this chapter, we will focus on the influence of age, gender, income, and possible combinations on private labels' purchases.

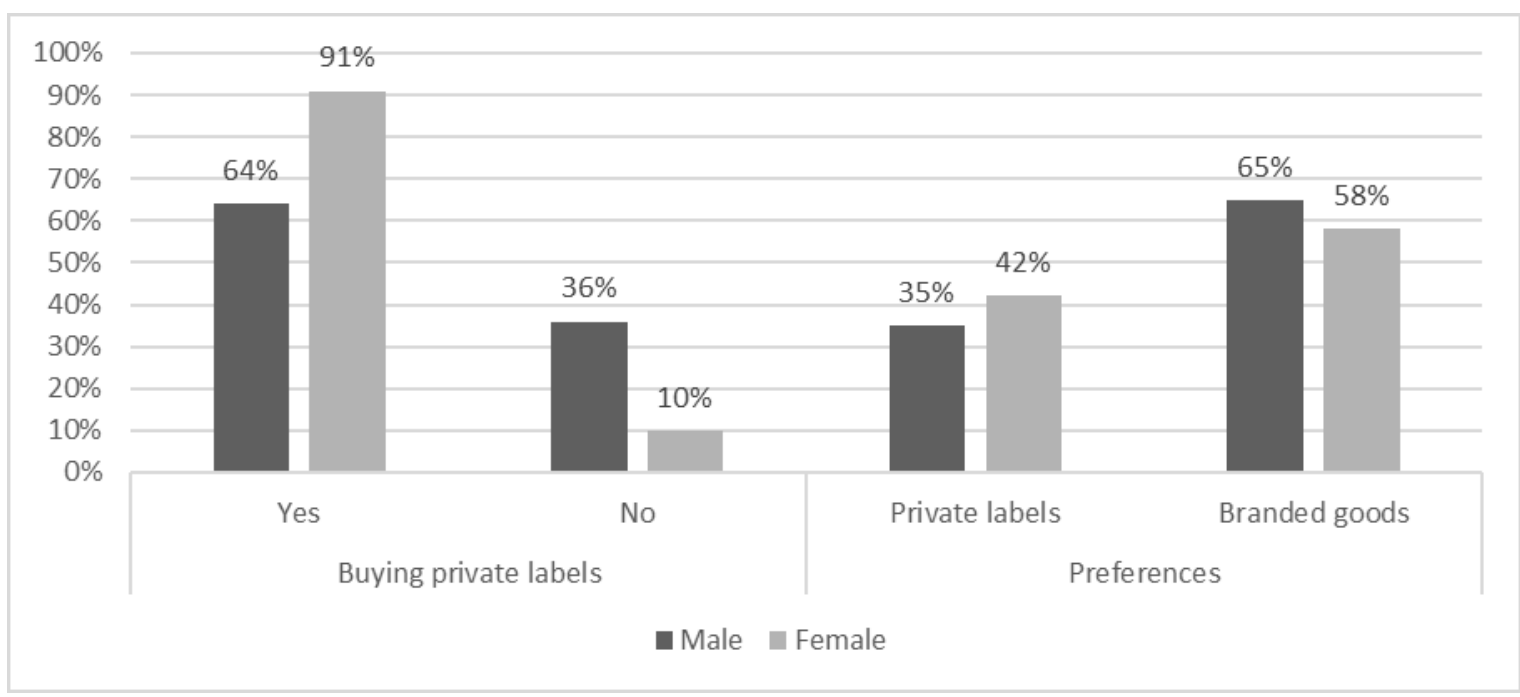

Figure 5. Private labels and their preferences by male and female in \%, Source: author's research.

As shown in Figure 5, most women buy private labels, 27\% more than men, but in the case of preferences, both men and women prefer branded goods. Of men who buy private labels, $63 \%$ said they prefer branded goods. The following graphs show preferences and the purchase of private labels depending on the average monthly income. 


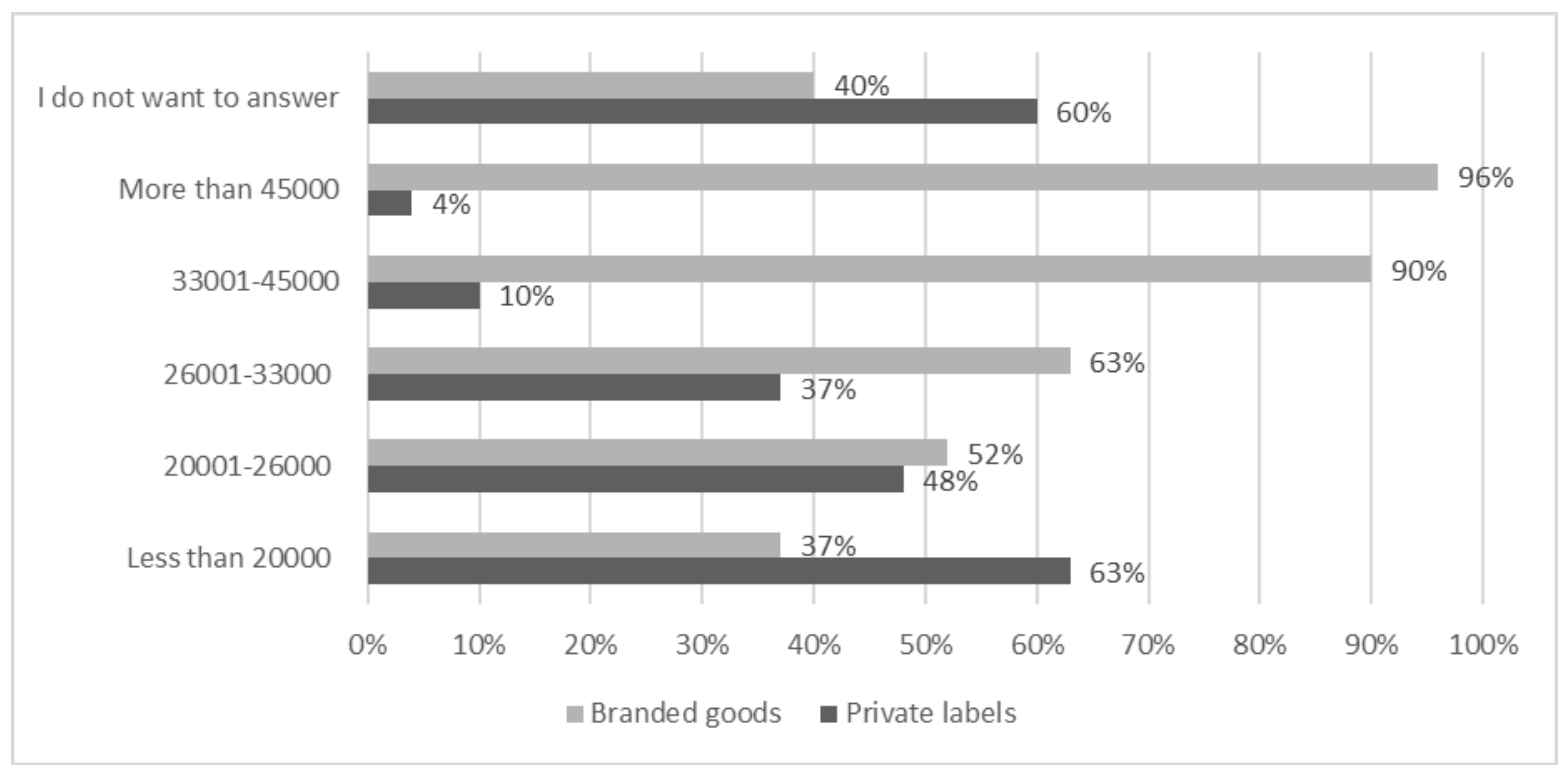

Figure 6. Preferences of private labels depending on the average monthly income (in CZK) in \%, Source: author's research.

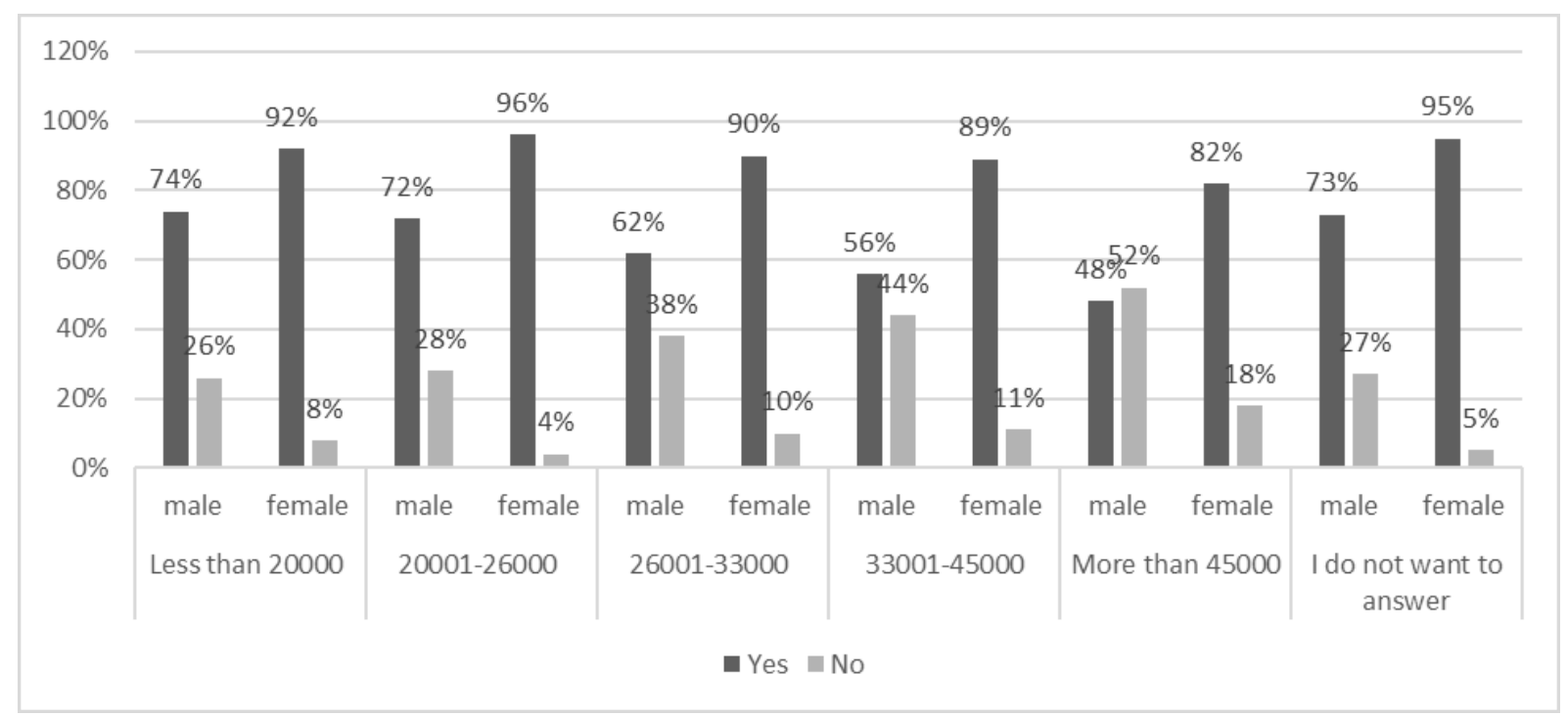

Figure 7. Purchase of private labels by male and female depending on the average monthly income (in CZK) in \%, Source: author's research.

As many authors point out, a distinction needs to be made between buying private labels and their preferences. It is very clear from the previous two graphs that higher income groups mostly prefer branded goods. Nevertheless, even so, these income groups buying private labels, too.

For example, the respondents from the highest income group with an average monthly income of more than $45000 \mathrm{CZK}$ stated in $96 \%$ that they prefer branded goods. Nevertheless, $82 \%$ of females and $48 \%$ of males stated that they are buying private labels. As mentioned above, private labels are bought by more women in all categories of average net income.

The following graph shows the redistribution of private labels according to individual age groups for males and females. 


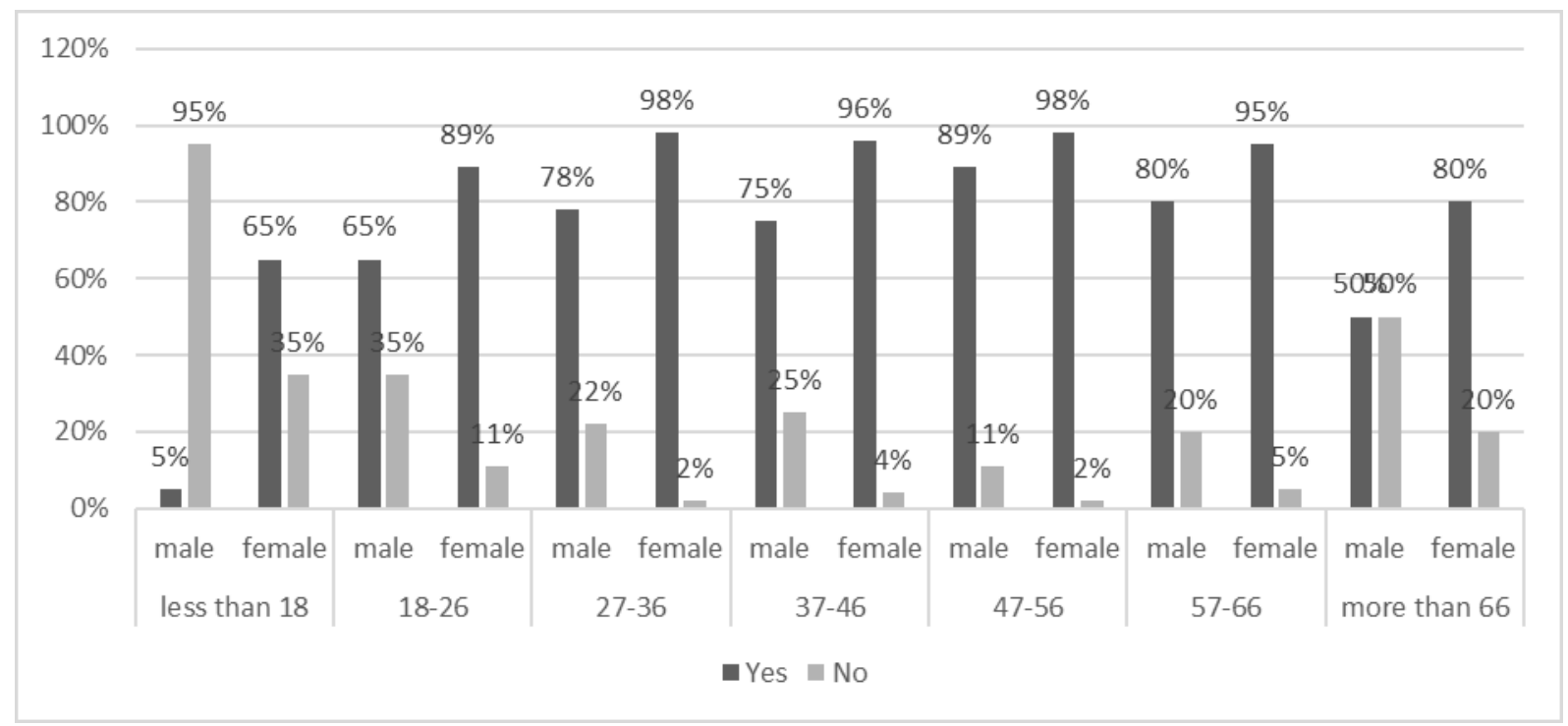

Figure 8. Purchase of private labels and different age groups in \%, Source: author's research.

In the case of age groups, there is much less interest in buying private labels from the youngest, especially men under 18 . However, it is necessary to realize that younger age groups up to 26 years are among those who prefer branded goods.

In the next part, we will deal with the influence of the customer's employment, the highest level of education attained, the number of household members, and the size of the place of residence on the purchase of private labels.

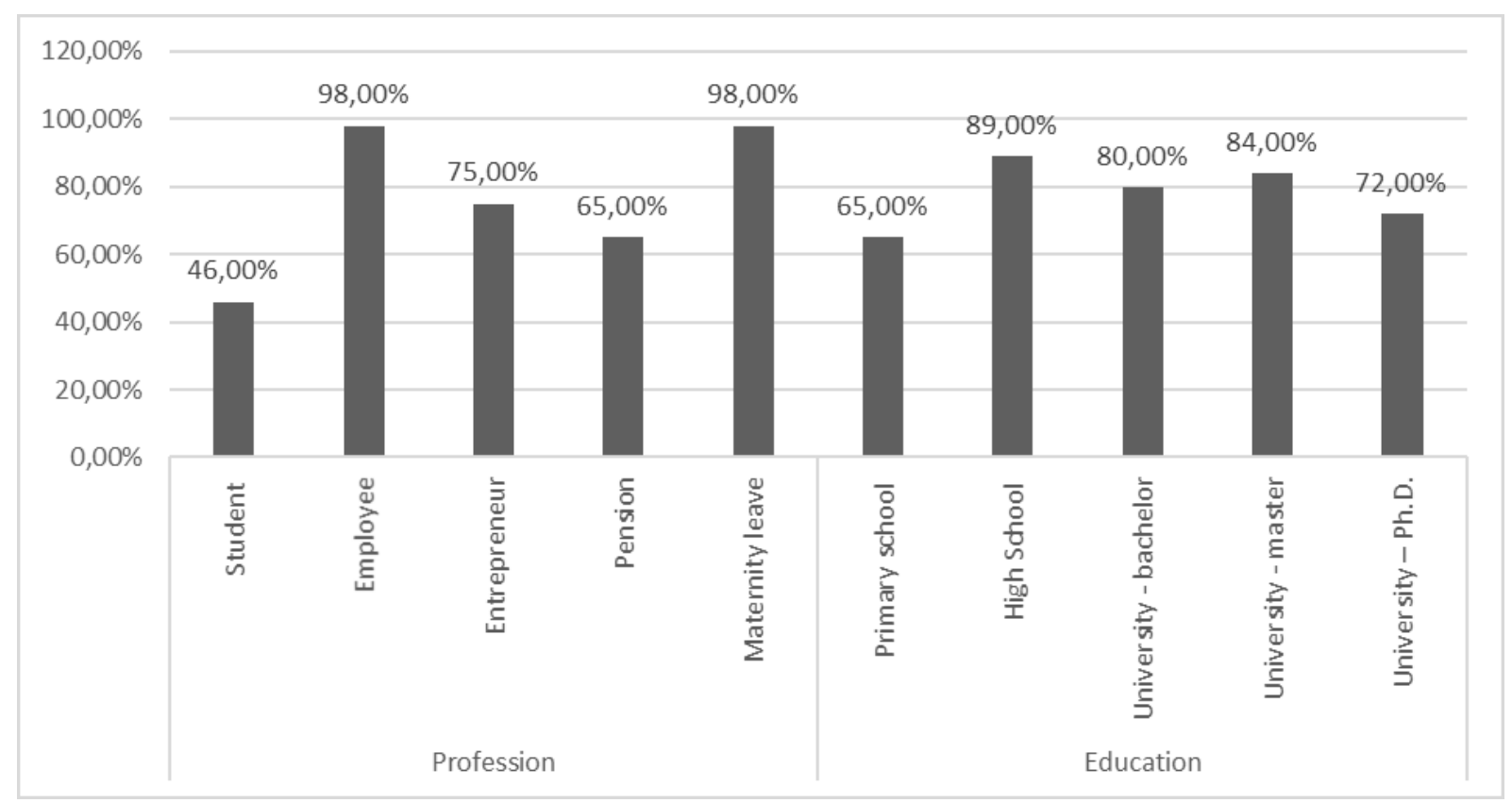

Figure 9. Profession and education in \%, Source: author's research.

Private labels are the least bought by students, pensioners, and people with primary education-however, most mothers are on maternity leave and employees. In terms of education, the distribution among other groups is relatively even. 


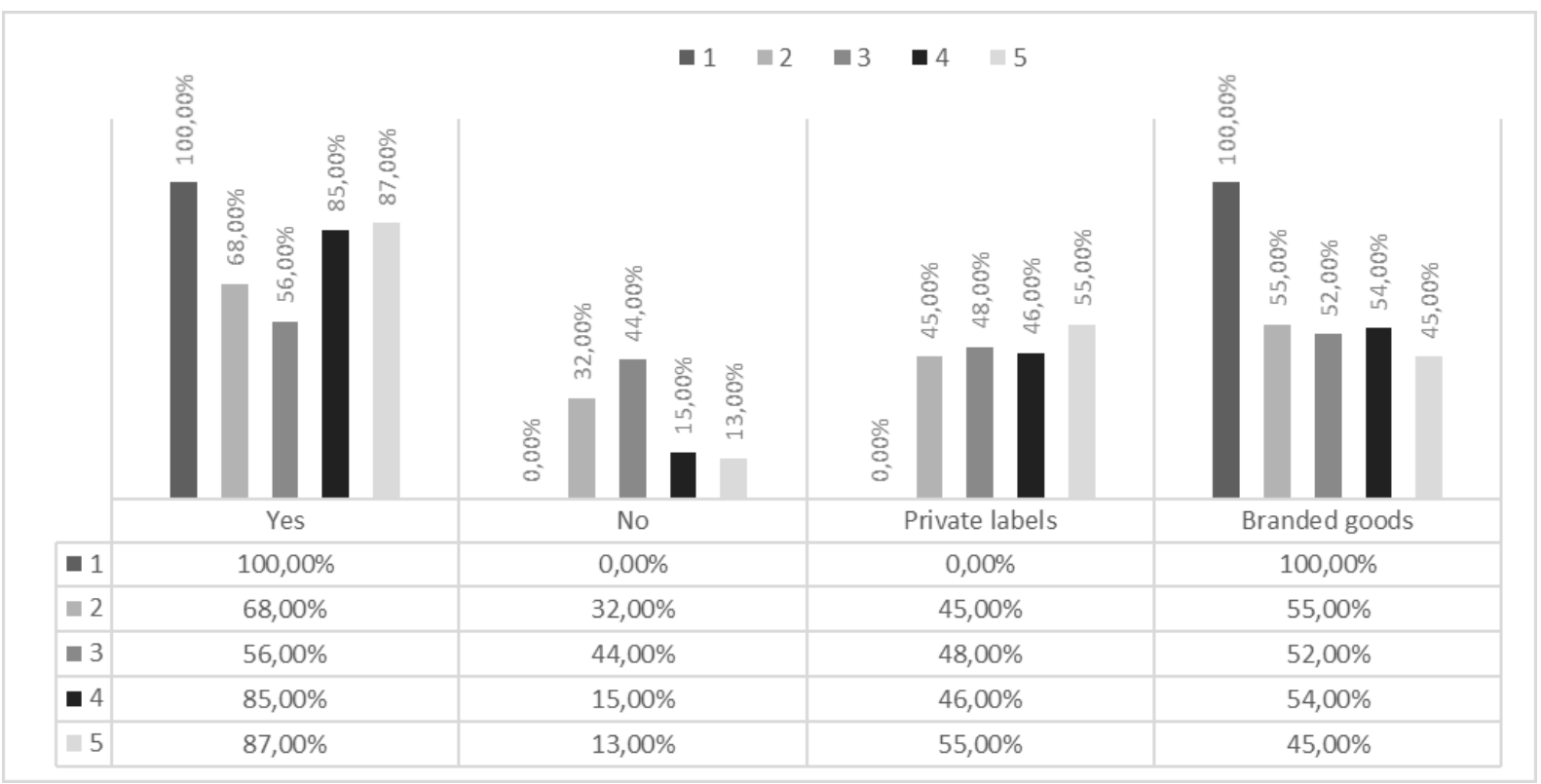

Figure 10. Private labels and number of household members in \%, Source: author's research.

Figure 10 focuses on individual types of households with different numbers of members. This figure shows whether they buy private labels and whether they prefer branded or non-branded goods. The least represented group was a household with one member (a total of $6 \%$ of respondents), whom all agreed that they buy private labels but prefer branded goods. Households with three members purchase private labels the least. However, they prefer branded and non-branded goods to about the same extent.

A closer examination of the purchase of private labels concerning the size of the residence revealed that people buy private labels more from medium and large cities. The least private labels are bought by people living in small towns and villages with a population of less than 1,000 . In this group, only $32 \%$ of respondents answered that private labels are bought.

\section{Summary}

Since private labels such as Cuneo et al. (2015), Kadirov (2020), Upadhyay, Vidhani, and Dadhich (2016), Janssen and Hamm (2014) point out, play a significant role in the current competition for customer retention, which has intensified during the Covid-19 pandemic, both customers and private labels need appropriate attention.

Not only for private labels, it is necessary to focus on the customer's profile and thorough knowledge, but it is also necessary to pay attention to the purchasing behaviour of customers, which is greatly influenced by the customer's profile, customer preferences, and approach to different brands.

This article aimed to examine the profile of a customer who buys and prefers private labels. Based on the author's research, it is possible to define several profiles of private label customers. 
The first segment is single women with an income of up to 20,000 CZK, aged under 27-36, who live in medium-sized cities with up to 100,000 inhabitants. Women with this private label profile not only shop but also prefer.

The second important segment of private labels are families with 1 to 2 children, with an average monthly income of 26,000 to 45,000 , primarily employees with a university degree at the bachelor's or master's level aged 27-46. Even in this segment, women also buy more private labels than men. However, this segment often prefers branded goods more than private labels.

The limitation of this research is the sample, which should be further expanded in the future and ensure an equal percentage of individual groups to apply statistical methods that would confirm the resulting customer profile of private labels. Further research will also focus on the differences in the profiles of customers buying different categories of private labels.

\section{References}

1. Chao, P. et al. (2008). Identifying the Customer Profiles for 3c-product Retailers: A Data Mining Approach. International Journal of Electronic Business Management, 6(4), pp. 195-202.

2. Cordo, J. (2012). Align S\&M Teams. Sales \& Service Excellence Essentials, 12(10), pp. 4-14.

3. Cuneo, A. et al. (2015). The growth of private label brands: A worldwide phenomenon? Journal of International Marketing, 23(1), pp. 72-90.

4. Eurostat (2021a). EU, development of retail trade volume. January 2020 - March 2021. Retrieved from https://ec.europa.eu/eurostat/statistics-explained/index.php?title=File:EU, _development_of_retail_trade_volume,_January_2020_-_March_2021_.png.

5. Eurostat (2021b). EU, development of retail trade volume during the Covid-19 crisis May 2021. Retrieved from https://ec.europa.eu/eurostat/statistics-explained/images/a/a1/EU $\% 2$ C_development_of_retail_trade_volume_during_the_Covid-19_crisis_May_2021.png.

6. Grosso, M., and Castaldo, S. (2015). Private Labels and National Brands: A Comparison Within Brand Extension. Advances in National Brand and Private Label Marketing Springer Proceedings in Business and Economics, pp. 95-102.

7. Hassan, M.M., Tabasum, M. (2018). Customer Profiling and Segmentation in Retail Banks Using Data Mining Techniques. International Journal of Advanced Research in Computer Science, 9(4), pp. 924-29.

8. Janssen, M., and Hamm, U. (2014). Governmental and private certification labels for organic food: Consumer attitudes and preferences in Germany. Food Policy, 49, pp. 437448. 
9. Julashokri, M. et al. (2011). Improving electronic customers' profile in recommender systems using data mining techniques. Management Science Letters, 1(2011), pp. 449-456.

10. Kadirov, D. (2020). Private labels ain't bonafide! Perceived authenticity and willingness to pay a price premium for national brands over private labels. Journal of Marketing Management, 31(17-18), pp. 1773-1798.

11. Lee, K.S., Yo, H., and Chung, S-Y. (2011). A Customer Profile Model for Collaborative Recommendation in e-Commerce. The Journal of the Korea Contents Association, 11(5), pp. 67-74.

12. Park, Y.J., Chang, K.N. (2009), Individual and group behavior-based customer profile model for personalized product recommendation. Expert Systems with Applications, 36(2), pp. 1932-1939.

13. Planiappan, S. et al. (2017). Customer Profiling using Classification Approach for Bank Telemarketing. International Journal on Informatics Visualization, 1(4-2), pp. 214-217.

14. Prasad, P., Malik, L.G. (2011). Generating Customer Profiles for Retail Stores Using Clustering Techniques. International Journal on Computer Science and Engineering (IJCSE), 3(6), pp. 2506-2510.

15. Risch, D., Schubert, P. (2005). Customer Profiles, Personalization and Privacy. Proceedings of the CollECTeR 2005 Conference, Furtwangen. Retrieved from https://www.researchgate.net/publication/242263870_Customer_Profiles_Personalization _and_Privacy.

16. Statista (2021a). world: retail sales 2018-2022. Available at https://www.statista.com/ statistics/443522/global-retail-sales/.

17. Statista (2021b). Private label share of supermarkets' sales volume in Europe 2020, by country. Retrieved from https://www.statista.com/statistics/1194649/private-label-shareof-total-supermarkets-sales-volume-europe/.

18. Syakur, M.A. et al. (2018). Integration K-Means Clustering Method and Elbow Method For Identification of The Best Customer Profile Cluster. IOP Conf. Series: Materials Science and Engineering, volume 336. The 2nd International Conference on Vocational Education and Electrical Engineering (ICVEE) 9 November 2017, Surabaya, Indonesia. Retrieved from https://iopscience.iop.org/article/10.1088/1757-899X/336/1/012017.

19. The Nielsen Company (2018). The rise and rise again of private label. Retrieved from https://www.nielsen.com/wp-content/uploads/sites/3/2019/04/global-private-labelreport.pdf.

20. Upadhyay, T., Vidhani, A., Dadhich, V. (2016). Customer Profiling and Segmentation using Data Mining Techniques. IJCSC, 7(2), 65-67.

21. Vasilev, J. (2014). Creating a Customer Profile in a Credit Institution. International Journal of Advanced Research in Computer Science and Software Engineering, 4(1), pp. 1108-111. 
22. Wehmeyer, K. (2005). Aligning IT and marketing The impact of database marketing and CRM. Journal of Database Marketing \& Customer Strategy Management, 12(3), pp. 243256.

23. Wu, J. et al. (2007). Research on Customer Profile Integration of Telecom Enterprises Based on Ontology. Conference: Research and Practical Issues of Enterprise Information Systems II, Volume 1. IFIP TC 8 WG 8.9 International Conference on Research and Practical Issues of Enterprise Information Systems (CONFENIS 2007), October 14-16, 2007, Beijing, China. Retrieved from https://www.researchgate.net/publication/221296752 Research_on_Customer_Profile_Integration_of_Telecom_Enterprises_Based_on_ Ontology. 